\title{
Stability Improvement of an Unmanned Aerial Vehicle's Wing using Active Vibration Control
}

\author{
Ahmed A. Ali, Ph.D. \\ Asst. Prof. \\ Baghdad University \\ Engineering College
}

\begin{abstract}
Stability analysis of any precision mechanical system is an important issue to be managed. In the present work two methods of active vibration control had been studied on Unmanned Aerial Vehicle's Wing, controllers P, PI and velocity feedback (VF) were tested to enhance the stability of tested wing. Many types of unmanned aerial vehicles are used in applications required high stability like video recording for meteorological or space research, so attenuation of wing's vibration will improve the performance of camera and will facilitate guiding of the vehicle. Numerical and experimental analysis was performed, where a scaled wing with controlling loop was integrated in FE solver ANSYS.15. In experimental work ( piezoelectric PPA-1001 MIDE -USA, DAQ NI PCIE6321 .USA and TREK2205 ampliefier.USA) were used with Labview2015 software to perform controlling action of scaled wing fabricated totally in Lab. Piezoelectric smart material was used in present work to satisfy controlling action. A comparison between numerical and experimental measurements shows high degree of agreement. Also results show that both methods add noticeable enhancement on wing stability but with different percentage. Where the best controlling performance was for VF controller where with activation it facilitates control in guiding the vehicle's controlling loop more than $83 \%$ of wing's settling time was eliminated.
\end{abstract}

\section{General Terms}

Active Vibration Control

\section{Keywords}

Finite Element Analysis ; ANSYS; Piezoelectric; Unmanned Aerial Vehicle; wing; Labview..

\section{INTRODUCTION}

Over the last two decades, techniques based on the use of embedded piezoelectric materials have emerged as viable solutions for a large number of structural control problems and, consequently, have received considerable attention. In some applications like an unmanned aerial vehicle the stability can be improved by using piezoelectric material in controlling loop with different types of controllers. In [1] controlled of vibration for a smart beam was presented. This smart beam consists of actuators and sensors located at the root of a cantilever beam. Excitation is produced used a white noise signal to the actuator. The piezoelectric sensors are used to measure the vibration. Simultaneously, feedback controller sends correction measurement to the actuator to reduce the vibration. To optimize results, controller was designed using optimal control strategy (Linear Quadratic Gaussian) (LQG) theory. The result related to this theory is high-order controllers. Authors in [2] Studied active vibration control. The vibration of a smart structure is suppressed by using counter directional force to the structure. A smart aluminum plate with included couple of piezoelectric lamination is used to analysis the active vibration control. The smart plate is rectangular aluminum beam and modeled in cantilever beam with bonded by piezoelectric patches. The FEM of the smart plate is modeled by uses ANSYS-12 software. Optimal sensor locations are obtained. A suitable control methodology found in the experiment study by optimize the controller constant gain to obtain more effective vibration control with min. control input. Author of [3], perfumed vibration suppression of smart structure by using smart material (piezoelectric). The smart structure consists of a beam as the master structure and piezoelectric patches as the sensing and actuation elements. Experimental has been done to obtain the active vibration control of smart structure. Experiments are complete for different specimen of smart beam. The theoretical finite element modeling is obtained by coupled efficient layer wise (zigzag) theory. Reference [4] presented output feedback based on active vibration control has been accomplished on smart structure (cantilever beam) used Lead ZirconateTitanate (PZT) actuators and sensors to remove from mechanical system undesirable vibrations during their operations. Three PZT patches were used, one as the shaker providing force vibrations, one as the sensor and the third as the actuator. The designed algorithm has been accomplished on Lab VIEW 2010 on Windows 7 Platform. Reference [5] studied simulations and research results of testing of the aluminum plate with active vibration control; it analyzed and compared two ways of excitation of the test plate, various influences on its vibrations and active damping control. Vibration control of the smart structure is realized through four piezoceramic PZT actuators and one PZT sensor bonded to the plate. Simulations and numerical computations of the structure are performed in ANSYS environment. Authors of [6] used vibration control of flexible plate by classical proportional feedback gain controller, method is studied experimentally. The AVC-P controller design is implemented to a full clamped flexible plate system to evaluate its vibration attenuation performance. In [7] authors were used model smart structures with piezoelectric materials product in ANSYS/Multi physics, the integration of control actions into the ANSYS solution is realized.

\section{FINITE ELEMENT MODEL}

Wing was scaled down by $(1 / 2.2)$ so as to coincide with test section of the wind tunnel for further tests. The wing is of an unmanned aerial vehicle, rectangular and un-swept the airfoil profile chosen to be NACA (0006) i.e. symmetric airfoil with a maximum thickness of $(6 \%)$ of the chord length. The modeling process is as follows:

1-The airfoil was drawn by (ANSYS 15) software with coordinate of $(y, z)$ as it shown in figure $(1)$, then lines were 
formulated to connect these points to generate out border of NACA section as stated in figure(2).

2-[al] command will form airfoil section, this section was extended via [Voffst] command to generate total FE wing in ANSYS as shown in figures (3), (4) respectively. Dimensions of tested formulated wing are stated in table. 1

3- Element [Solid 45] was selected for meshing of tested wing, with element size of 0.1 which was formulated by [esize] command. This type of element is very useful for meshing 3D composite structures. Total meshed 3D model is presented in figure (5). SOLID 45 has a quadratic displacement behavior and is well suited for modeling irregular meshes. The element is defined by 10 nodes having three degrees of freedom at each node: translations in the nodal $\mathrm{x}, \mathrm{y}$, and $\mathrm{z}$ directions, also element has plasticity, creep, stress stiffening, large deflection, and large strain capabilities. SOLID5 was used to mesh piezoelectric transducers (PZT). [Da] command was used to fix the wing root in ANSYS environment where all degree of freedom was fixed at airfoil root. Total boundary conditions for free vibration model are presented in figure (6)[8].

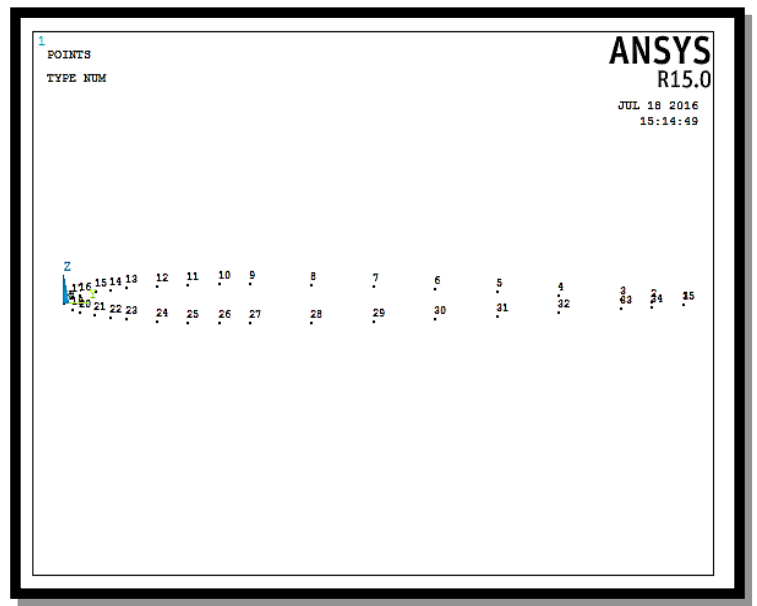

Fig.1 Points of airfoil section of tested wing

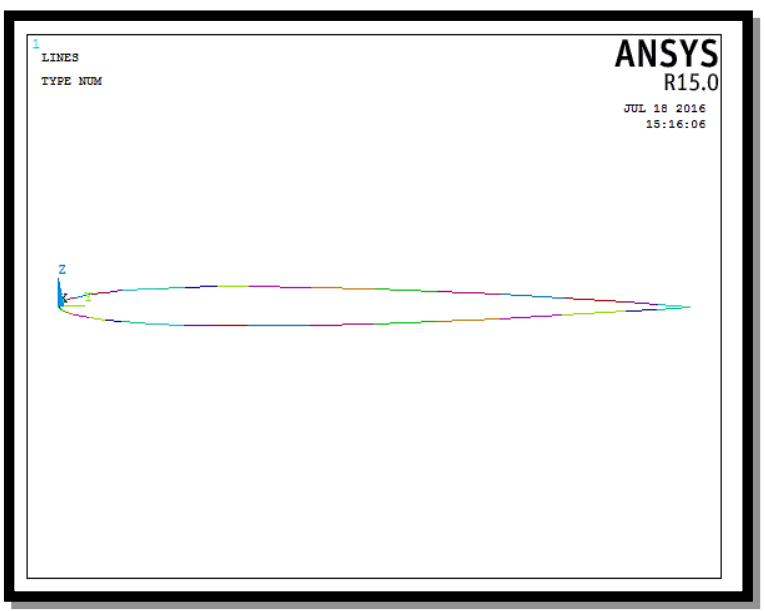

Fig.2 Airfoil's border of tested wing

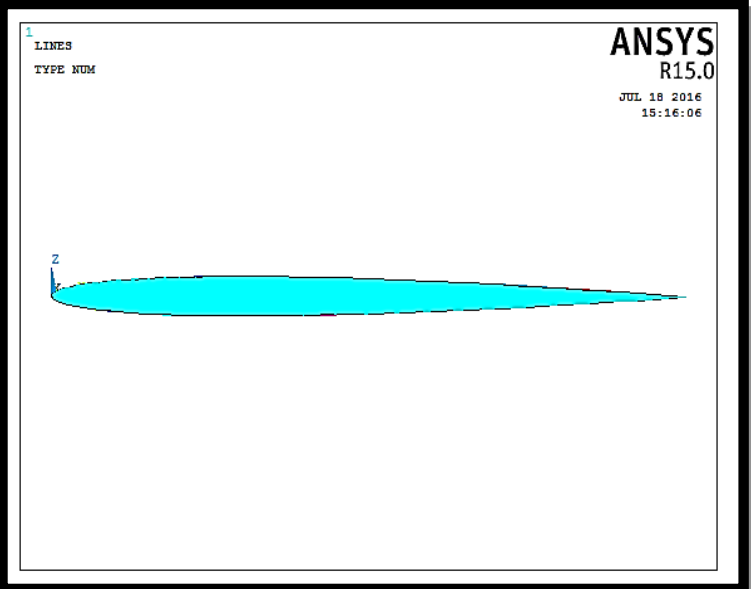

Fig.3 Airfoil section of tested wing

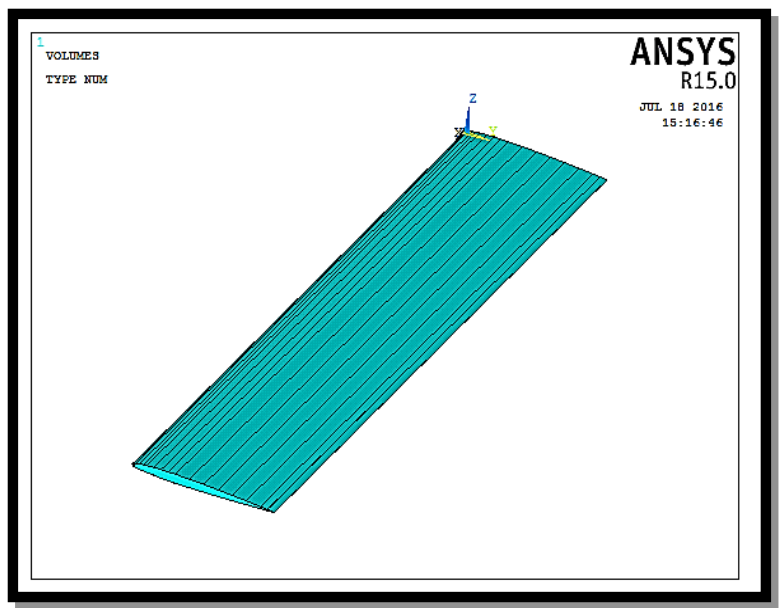

Fig.4 Tested wing

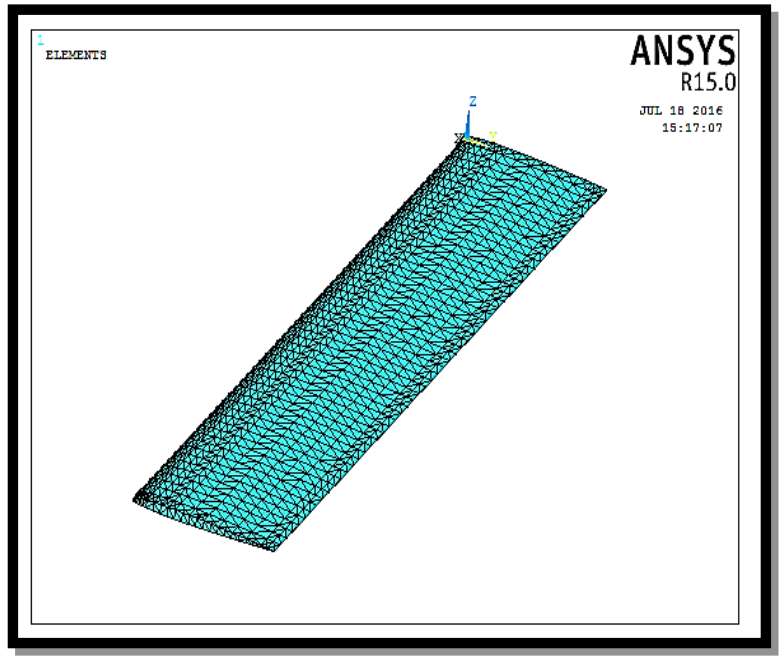

Fig.5 Total meshed of tested wing 


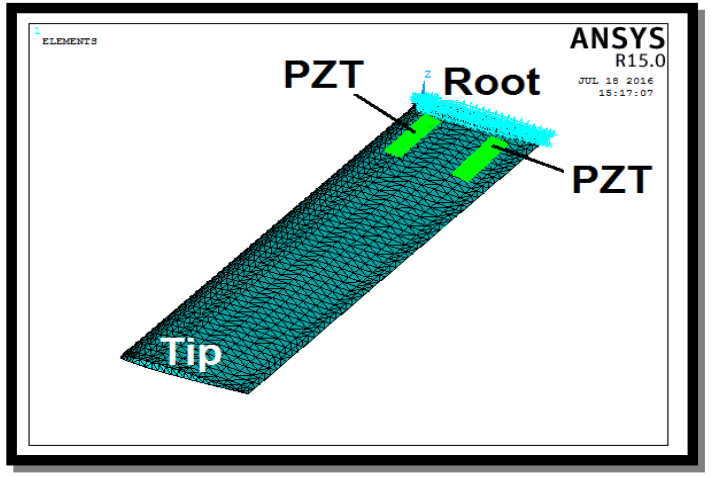

Fig.6 Boundary condition of tested wing

\section{EXPERIMENTAL MODEL}

Total wing similar to FE model was manufactured experimentally where a laminated beam with a six ply of $(0.53 \mathrm{~mm})$ ply thickness was manufactured from woven Eglass/polyester. Foam core was prepared to create the profiles of the leading and trailing edges skin of the wing was created by one ply upper and lower surface, the resulting model is a beam of (8 layers with $4.24 \mathrm{~mm}$ thickness ) and leading and trailing edge skin of (1 layer with $0.53 \mathrm{~mm}$ thickness). To obtain a fresh surface the model was coated by very thin film of putty and then painted. All steps of manufacturing process are presented in figure (7). Woven E-glass fiber, polyester resin, Hardener, Isolating material (trelac) used to isolate the laminate from the surface of the work; window glass was used as a suitable surface. Cotton roller used for resin lamination Teethed aluminum roller used for compressing the fibers and also extrude air bubbles, thinner used for cleaning the aluminum roller from the polyester after the compression process.

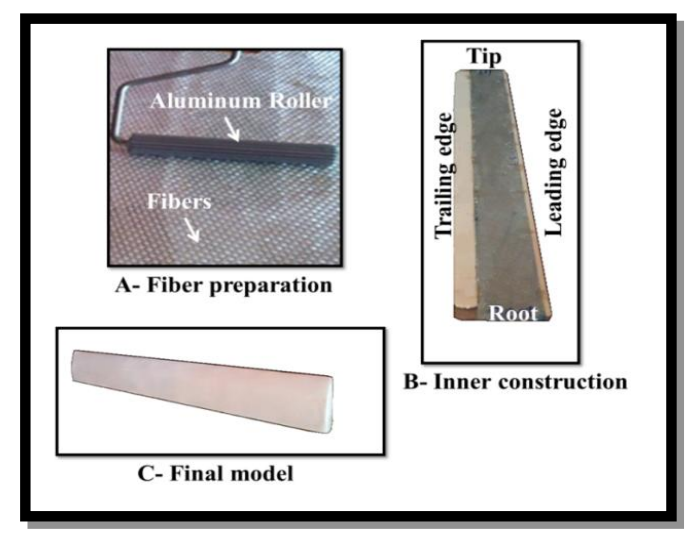

Fig.7 Experimental manufacturing steps

\section{CONTROLLING LOOP}

Two controlling techniques were used for vibration suppression of tested wing numerically and experimentally, where proportional integral controller beside velocity feedback were totally integrated and formulated in ANSYS.15 by using direct programming method. Tested wing was excited to be vibrated freely while recording its response and then controlling loop was activated for further excitations to present the effect of controllers. For the free vibration due to initial displacement, static analysis is performed by applying the initial displacement to the tip of the smart aircraft wing. All nodal displacements are obtained for the initial displacement of the tip and save these displacements in matrix form. Initial condition is described using these nodal displacements for all nodes of the smart aircraft wing and then applied these displacements as initial condition (IC) to obtain free vibration due to Initial displacement. Initial displacement at the tip of smart aircraft wing is obtaining approximately from application of aerodynamic forces.

\section{PI CONTROLLER}

The block diagram of the analysis for active vibration control in smart structures is show in figure 8. Free vibration is performed due to applying aerodynamic force (lift force) on the aerodynamic center of the smart aircraft wing at the analysis of the first time step (before beginning of closed loop system) and then give this force zero at the beginning of closed loop system to obtain free vibration due to force. $\mathrm{K}_{\mathrm{C}}$ and $\mathrm{K}_{\mathrm{V}}$ are the control and power amplification factors, respectively. $\mathrm{K}_{\mathrm{V}}$ is taken as 100 by inspection PZT amplifier gain. The voltage values $\left(\mathrm{V}_{\mathrm{S}}\right)$ of the sensor location are taken as the feedback loop. The nodes at the bottom and top surfaces of the sensor and actuator are coupled for the degrees of freedom, VOLT. The proportional control $\left(\mathrm{K}_{\mathrm{C}}\right)$ is only applied. Thus, the proportional constant for the voltage of actuator $\left(\mathrm{V}_{\mathrm{A}}\right)$ is the multiplication of $\mathrm{K}_{\mathrm{C}} * \mathrm{~K}_{\mathrm{V}}$. The value of actuator voltage $\left(\mathrm{V}_{\mathrm{A}}\right)$ is changed in each time step corresponding to the voltage sensor $\left(\mathrm{V}_{\mathrm{S}}\right)$ and the multifunction of $\mathrm{K}_{\mathrm{C}}$ and $\mathrm{K}_{\mathrm{V}}$ are constant in each time step. The calculated deflection $U_{Z}$ is observed to evaluate the performance for the response of vibration control. Effective actuation and sensing of control action depend on the locations of actuators and sensors. The actuator and sensor locations are very important to obtain maximize actuator effective. The positions of the maximum strain in aircraft wing are the best locations for actuators. The objectives of the control are to place all of the actuators and sensors in multi different areas. Modal analysis of the aircraft wing is required to design the locations of actuators and sensors. PID algorithm is described by:

$u(t)=K\left(e(t)+\frac{1}{T_{i}} \int_{0}^{t} e(t) d t+T_{d} \frac{d e(t)}{d t}\right)$

The controller parameters are proportional gain $\mathrm{K}$, integral time $\mathrm{Ti}$, and derivative time $\mathrm{Td}$. In the present study only $\mathrm{P}$ and I are activated in PID controlling loop. Values of each term were selected by trial and error for formulating range of acceptable values of gains to be used [9].

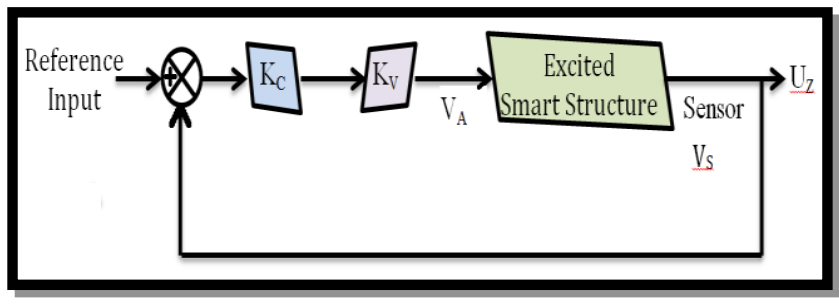

Fig.8 Block diagram of analvsis

\section{VF CONTROLLER}

Dynamic presentation of tested wing is presented in equation (2), Where $\mathrm{M}$ mass, $\mathrm{F}$ force and $\mathrm{K}$ stiffness.

$m \ddot{\delta}+k \delta=f+\beta q$

In order to present the total effect of controller, the damping term was omitted and based on general equation of velocity feedback. Controlling force denoted by $\mathrm{q}$ where $(\mathrm{q}=\mathrm{C} \dot{\delta}, \mathrm{C}$ : controller gain) while $\beta$ is the influence matrix. So it was noted that adding of controller term leads to improve the damping behavior of tested structure. Block diagram of velocity controlling technique are shown in figure (9) [9]. 


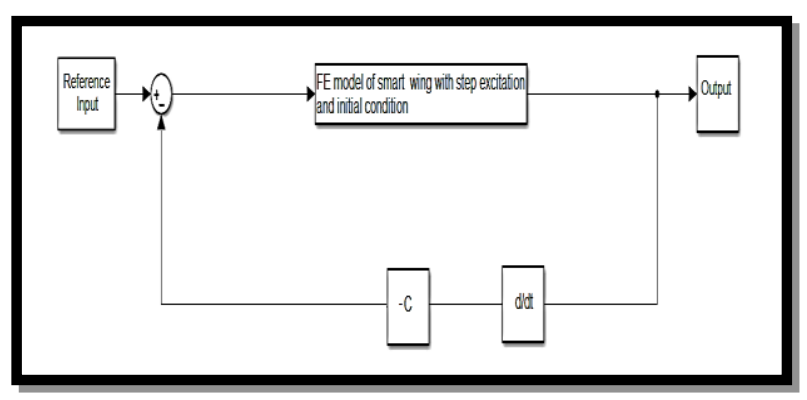

Fig.9 Block diagram of VF

Table.1 Material Properties

\begin{tabular}{|c|c|}
\hline $\begin{array}{l}\text { PPA-1001 } \\
\text { Piezoelectric actuator }\end{array}$ & $\begin{array}{l}\text { Epoxy-glass composite } \\
\text { structure }\end{array}$ \\
\hline $\begin{array}{l}\rho=7350 \mathrm{~kg} / \mathrm{m}^{3} \\
\text { Piezoelectric } \\
\text { strain matrix } \\
\left(C / \mathbf{m}^{2}\right) \times 10^{9} \\
\text { E31 }=6.5 \\
\text { E33 }=23.3 \\
\text { E15 }=17 \\
\text { Elastic stiffness } \\
\text { matrix }\left(\mathrm{N} / \mathrm{m}^{2}\right) \\
\text { C11 }=12.6 \\
\text { C12 }=7.95 \\
\mathrm{C} 13=\mathbf{8 . 4 1} \\
\text { C33 }=11.7 \\
\text { C44 }=2.33 \\
\text { Dielectric matrix } \\
(\mathrm{F} / \mathrm{m}) \times 10^{-9} \\
\text { e11 }=1.503 \\
\text { e22 }=1.503 \\
\text { e33 }=1.3\end{array}$ & $\begin{array}{l}\rho=1830 \mathrm{~kg} / \mathrm{m}^{3} \\
\mathrm{Ex}=40.51 \mathrm{GPa} \\
\mathrm{Ey}=13.96 \mathrm{GPa} \\
\mathrm{Ez}=13.96 \mathrm{GPa} \\
\mathrm{Gxy}=3.1 \mathrm{GPa} \\
\mathrm{Gyz}=1.55 \mathrm{GPa} \\
\mathrm{Gxz}=3.1 \mathrm{GPa} \\
v x y=0.22 \\
v y z=0.11 \\
v x z=0.22\end{array}$ \\
\hline
\end{tabular}

\section{EXPERIMENTAL SETUP}

The Experimental setup Laboratory is shown in Figures 10. In the experimental setup, a multifunction analog input / analog output (NI PCIE - 6321 express data acquisition with high performance $\mathrm{PC}$ ) is utilized for data acquisition and controlling action this device was equipped with SCB-68A screw terminal for wire connections. The PZT are used as actuators and sensor where PPA-1001 (MIDE -USA) transducer was used as actuator that performs controlling effect. While Accelerometer 4344 (B\&K - Denmark) was used as sensor for fed back the response to controlling loop. BNC cable with highly shielded wires were utilized to prevent any effect of disturbances on sensed responses. Controlling loop was totally formulated in labview .15 to perform controlling action for both PI and VF controllers. A maximum applied voltage was 120 v. Saturation tool in Labview program was used to level off actuation voltage to be within the limit of PPA-1001 voltage. High voltage amplifier TREK 2205 with $220 \mathrm{~V}$ power supply was used to amplify the controller's output signal, while (2626 B\&K - Denmark) was used for conditioning and amplifying the sensed accelerometer signal. Metallic frame was fabricated for firmly fixation of tested wing in a similar manner of simulated model. From mentioned figure a simple personification of controlling loop is presented here:

1- An excitation of $1 \mathrm{~cm}$ was applied on the wing tip.

2- A calibrated 4344 accelerometer sensed the applied displacement.

3- Conditioning and amplification effect was performed on sensed signal via (2626 preamplifier).

4- Transferring signal to (NI PCIE - 6321 express data acquisition) in analog input pin.
5-Digital signal is then imported to controller loop that was built in Labview software.

6- Output actuation voltage is transmitted to TREK 2205 amplifier for feeding PZT.

7- PZT will applied actuation force that can attenuate excitation effect.

8- Steps from 1 to 7 will be repeated until performing the settling of wing.

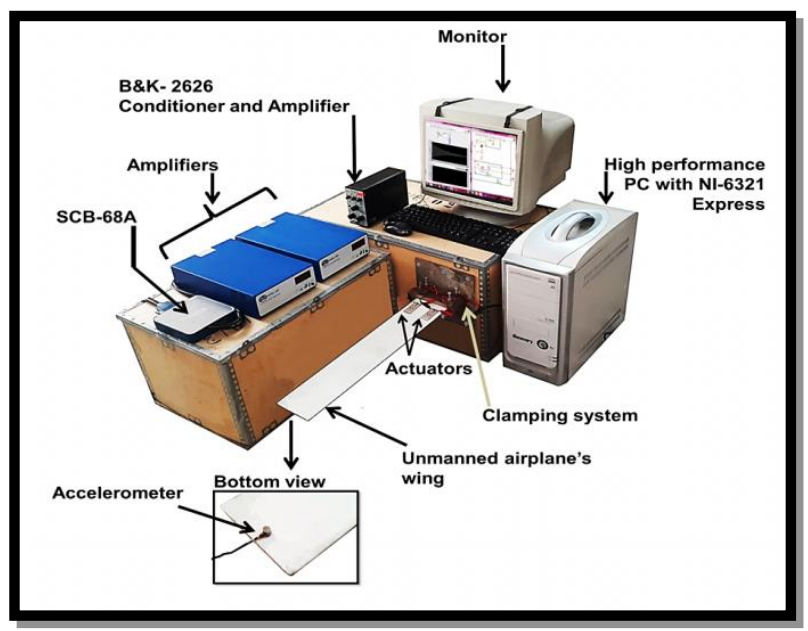

Fig.10 Experimental setup

\section{RESULTS AND DISCUSSION}

In the present work, first six natural frequencies with their corresponding modes had been estimated in ANSYS.15 by using block lanczos method. Figure (11) presents the calculated modes for tested wing without PZT. It was noticed that there was an increasing of about $0.3 \mathrm{~Hz}$ in first modes when they were calculated for wing equipped with PZT. Since the amount is insignificant, its effect will be neglected.

This insignificant increasing was because of adding more stiffness for wing but since the wing was originally much stiffed not big increasing was noticed. Modes are presented to validate the first mode shape and how it coincides with studied vibrational case of the present work in which the wing was excited to be vibrated in similar behavior of first mode. Free and controlled responses with P and PI controller are presented in figure (12) in which proportional gain was $(\mathrm{Kp}=1.5, \mathrm{Kp}=3)$ where it was selected by trial and error. Form this figure it was noticed that increasing proportional gain will decrease the settling time and add more stability to wing, but the increasing of proportional gain was not open for wide range of gains where high increasing may effect on fluctuating wing instead of suppressed its oscillation. In addition, responses with PI controller are presented in figure (12) in which gains for proportional and integral terms are $(\mathrm{Kp}=3, \mathrm{Ki}=1.5$ and $\mathrm{Kp}=3, \mathrm{Ki}=3)$. Adding of integral term will lead to increase the voltage of actuation that makes the system more rapid to settle after impulse excitation. Responses with velocity feedback controllers are presented in figure (13) for gain of $0.7,1$ and 1.5 respectively. From this figure a proportional relation was noticed between gain and actuation voltage, but it was observed that using gain of 1.5 will eliminated $80 \%$ of settling time. A comparison between mentioned methods shows that VF add more damping and was more effective in vibration suppression of unmanned aerial vehicle's wing. Experimentally measured responses are presented in figure (14) in which free and controlled responses with gains of $(\mathrm{kp}=3)$ and $(\mathrm{kp}=3, \mathrm{ki}=3.5)$ are 
presented respectively. In figure (15) experimentally measured responses for both free and controlled with velocity feedback controller of gain equal to 3 are presented. High degree of agreement was noticed by comparison between numerically and experimentally measured responses. Where the error percentages between experimentally and numerically estimated settling time was not exceed $4.1 \%, 5.5 \%, 2.6 \%$ and $3.1 \%$ for free, controlled with P, PI and VF respectively. This agreement proves the validity of followed steps in measuring free and controlled responses.

\section{CONCLUSIONS}

It was noticed that using PZT as actuators and sensors can improve controller effectiveness due to their both high sensitivity and actuation performance. Also it was noticed that using of $\mathrm{P}$ and PI controller are effective in vibration suppression for case of slow suppression velocity. Main concluded point was that VF shows high performance than both $\mathrm{P}$ and PI controller where it eliminated $80 \%$ of oscillation time with actuation voltage of 100 volt for each PZT. More service life is expected for VF in comparison with both P, PI where one can eliminate the oscillation with low amounts of voltages to reach similar P or PI limit with low voltage amount.

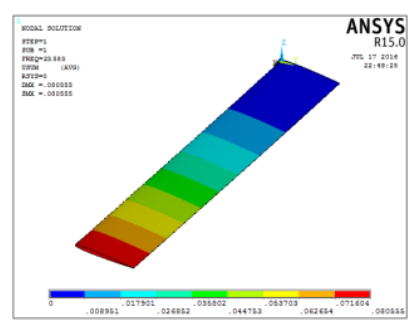

a. 1 st mode

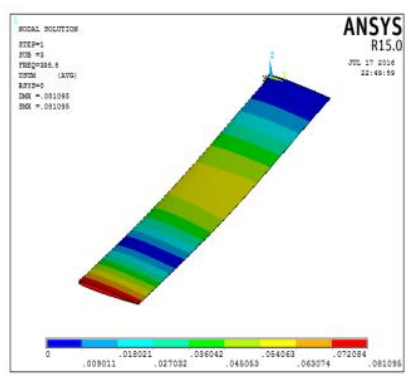

c. 3 rd mode

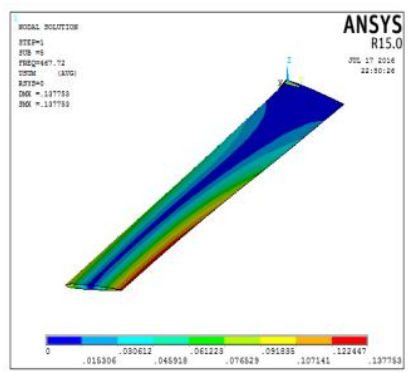

e. 5 th mode

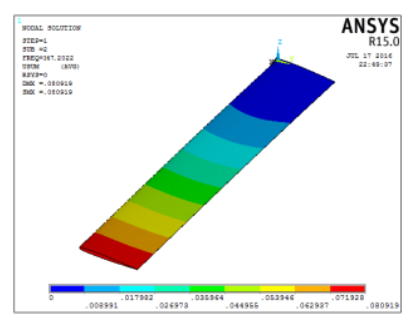

b. 2nd mode

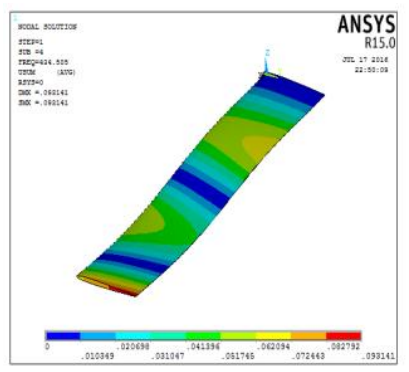

d. 4th mode

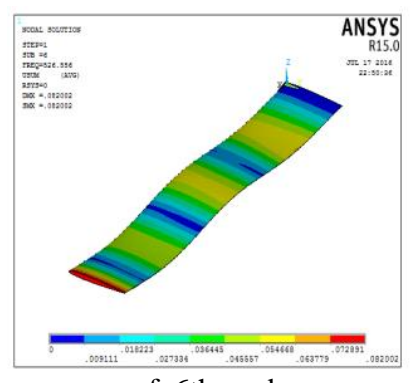

f. 6 th mode
Fig. 11 Mode shape of tested wing

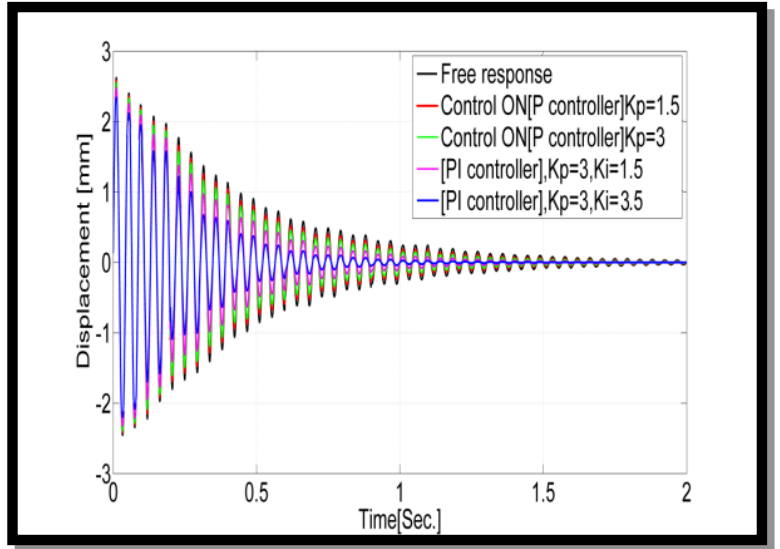

Fig.12 Numerically measured free and P, PI control responses of tested wing.

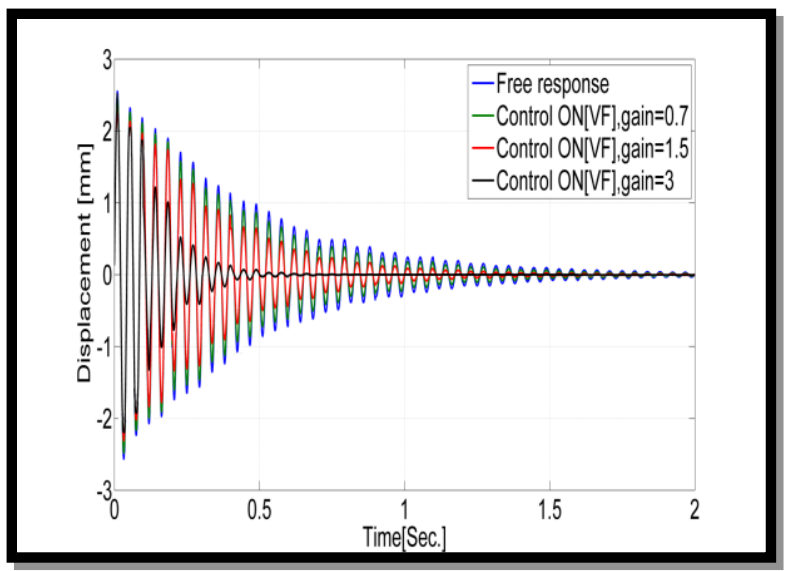

Fig.13 Numerically measured free and VF control responses of tested wing

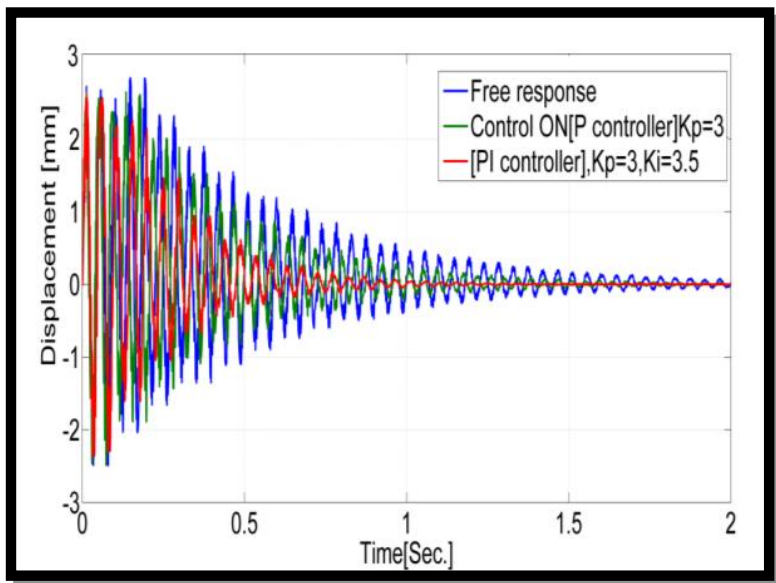

Fig.14 Experimentally measured free and P, PI control responses of tested wing 


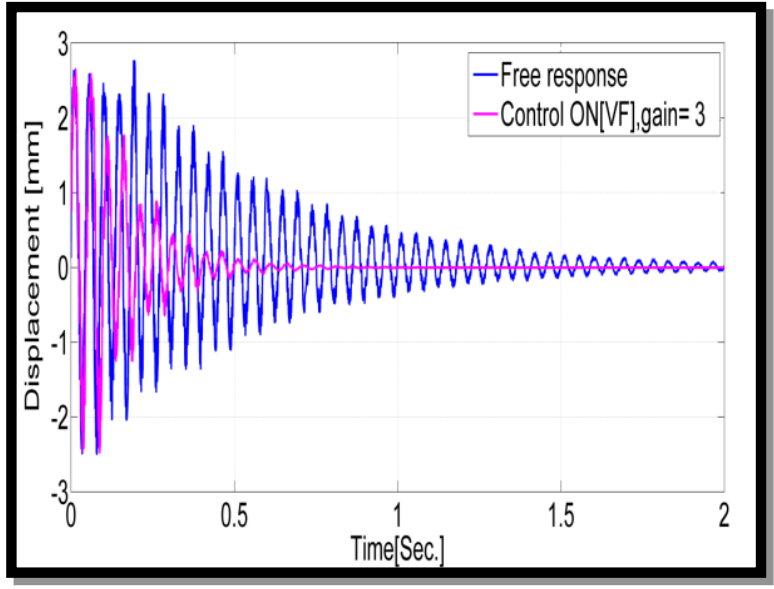

Fig.15 Experimentally measured free and VF control responses of tested wing

\section{REFERENCES}

[1] K. B. Waghulde, Bimleshkumar Sinha, M. M. Patil, and S. Mishra, "Vibration Control of Cantilever Smart Beam by Using Piezoelectric Actuators and Sensors" International Journal of Engineering and Technology Vol.2(4), 2010, 259-262.

[2] Joy Baral, Peenak Chatterjee, and Sidharth Das, "Active Vibration Control of Piezo-laminated Cantilever Beam", Department of Mechanical Engineering, National Institute of Technology, Rourkela, Orissa MAY 2011.

[3] Najeeb ur Rahman and M. Naushad Alam "Active Vibration Control of a Piezoelectric Beam Using PID Controller", Department of Mechanical Engineering, Aligarh Muslim University, Aligarh,U.P-202002, India, 24 May 2012, $657-673$.

[4] A.P. Parameswaran, A.B. Pai, P.K. Tripathi, and K.V. Gangadharan, "Active Vibration Control of a Smart Cantilever Beam on General Purpose Operating System" National Institute of Technology, Surathkal-575 025, India, Defence Science Journal, Vol. 63, No. 4, July 2013, pp. 413-417.

[5] M. Kozupa and J. Wiciak " Active Vibration Control of Rectangular Plate with Distributed Piezoelements Excited Acoustically and mechanically" / University of Science and Technology AGH al. Mickiewicza Vol.3, pp.30-059 Krakow, Poland/2010.

[6] T. A. Zahidi Rahman , I. Z. M. Darus ."Experimental Evaluation of Active Vibration Control of a Flexible Plate using Proportional Gain Controller". IEEE, 2011.

[7] H.Karagu, L Malgaca and H .ktem. "Analysis of active vibration control in smart structures by ANSYS". Smart Materials and Structures Vol.13, pp.661-667, 2004.

[8] ANSYS user manual,(2014) ANSYS user manual (version 15.0). USA: ANSYS, Inc. www.ansys.com, 2014.

[9] Katsuhiko Ogata. Modern Control Engineering .5th Edition. Pearson education Inc. 2011. 